\title{
doispontos:
}

\section{Vida prática e pragmatismo em Bergson ${ }^{1,2}$}

\author{
Stéphane Madelrieux \\ Université Jean Moulin - Lyon 3/IRPHIL, Lyon, France \\ stephane.madelrieux@univ-lyon3.fr
}

\begin{abstract}
Resumo: No Ensaio sobre os dados imediatos da consciência, Bergson chama de "vida prática" o conjunto das exigências sociais da comunicação que podem vir a se interpor entre uma consciência pessoal e ela mesma. Sete anos mais tarde, em Matéria e memória, são as urgências biológicas da ação que mais fundamentalmente definem a vida prática e que passam a se interpor entre o espírito e a realidade. O que se passou durante esse intervalo de tempo? A hipótese que se pretende defender no presente artigo é que tal mudança ou correção de ponto de vista se deve à leitura, por Bergson, dos Princípios de Psicologia que William James publicou em 1890, primeiro livro de psicologia funcional que já anuncia o seu pragmatismo como uma teoria naturalista do conhecimento. No desenvolvimento desta hipótese procuraremos defender, ainda, que a influência de Willian James sobre o pensamento de Bergson, se deve, assim, mais a sua psicologia da ação do que a sua psicologia da introspecção.
\end{abstract}

Palavras-chave: Bergson; Willian James; Vida prática; Pragmatismo.

\section{Practical life and pragmatism in Bergson}

Abstract: In the Essai sur les données immédiates de la conscience Bergson calls "practical life" the set of social demands of communication that may come between a personal consciousness and itself. Seven years later, in Matière et Mémoire, are the biological urgencies of action that more fundamentally define the practical life and that come to interpose between the spirit and the reality. What happened during this time? The hypothesis that it is intended to defend in the present article is that this change or correction of point of view is due to the reading, by Bergson, of the Principles of Psychology that William James published in 1890, first book of functional psychology that already announces its pragmatism like a naturalistic theory of knowledge. In the development of this hypothesis, we will try to argue that the influence of William James on Bergson's thought is thus due to this psychology of action rather than his psychology of introspection.

Key-words: Bergson; William James; Practical life; Pragmatism.

Quando se fala de "vida prática", evoca-se no mais das vezes um vago subconjunto de nossas atividades cotidianas, próximo aos lazeres, ao trabalho ou ao esporte. As seções "vida prática" das revistas gostam de nos aconselhar sobre a melhor maneira de plantar couves, assar um coelho, furar uma parede ou consertar o carro, sem esquecer do preenchimento da declaração do Imposto de Renda. Bergson, ao contrário, tem uma concepção imensamente rica disso que ele chama de "vida prática": ela não é uma subcategoria de nossas atividades cotidianas, pois ela não se identifica apenas com o conjunto dessas atividades, mas também engloba, ou ao menos objetiva englobar, atividades que prontamente se julgariam como "teóricas" em relação às primeiras - como as ciências positivas. É que Bergson qualifica como "prático" o conjunto das relações que nós entretemos tanto com os outros quanto com os objetos visando a obter certos efeitos que nos interessam. Portanto, não apenas a bricolagem ou a cozinha distinguem a vida prática, mas toda 
atividade com uma finalidade, isto é, toda atividade que não é conduzida "por nada, por prazer", mas que tem em vista produzir um efeito útil. Assim, há pouquíssimas atividades como a filosofia - entendida como metafísica - ou como as ciências - quando estas não abandonam a busca do saber desinteressado -, que são estranhas à vida prática e que podem ser qualificadas como puramente "teóricas" ou "especulativas". Também seria preciso incluir uma atividade que parece à primeira vista prática e manipuladora, a arte, na medida em que o artista, supõe Bergson, percebe de maneira perfeitamente "desapegada" e não interessada.

Mas é igualmente importante, aos olhos de Bergson, não transpor para a filosofia as maneiras de pensar desenvolvidas para responder às necessidades da vida prática, pois é por não separar a especulação desinteressada do pensamento prático que se criam os falsos problemas que dividem os filósofos ou bloqueiam o progresso das ciências. A razão disso é simples: a necessidade prática ou o interesse se interpõe entre o filósofo e a realidade, de modo que o conhecimento que ele tem desta passa a ser relativo ao seu próprio ponto de vista ao invés de ser conhecimento do objeto nele mesmo e por ele mesmo. Se se quer alcançar um tal conhecimento absoluto e não mais relativo, é preciso de algum modo conseguir suspender ou neutralizar a relação prática que nós naturalmente temos com os objetos, as pessoas e nós mesmos. O jardineiro que planta sua couve será um autêntico cientista se, para além da promessa de uma boa sopa, ele vir nela um ser vivente de consciência adormecida. O mecânico será um artista se, no lugar de consertar veículos, empilhar 59 deles em 1600 toneladas de concreto ${ }^{3}$. E o cozinheiro será filósofo se, ao colocar seu coelho no fogo, constatar que é preciso esperar, pois ele não pode acelerar a velocidade de cozimento sem mudar a qualidade da carne.

Mas se Bergson permaneceu fiel, ao longo de sua obra, tanto em relação à exigência de tal separação quanto em relação à origem dos falsos problemas filosóficos, variou na sua maneira de definir a vida prática. Em 1889, no Ensaio sobre os dados imediatos da consciência, (BERGSON, 2007) ele chama de "vida prática" o conjunto das exigências sociais da comunicação que podem vir a se interpor entre uma consciência pessoal e ela mesma. Sete anos mais tarde, em 1896, em Matéria e memória (BERGSON, 2008a), são as urgências biológicas da ação que mais fundamentalmente definem a vida prática e que passam a se interpor entre o espírito e a realidade. É porque devemos viver e agir em um ambiente natural, e não somente porque devemos falar e nos comunicar em um meio social, que somos expostos às ilusões sobre nós mesmos e sobre a realidade quando transpomos ao plano do conhecimento teórico aquilo que não vale senão para as necessidades da vida prática. O que se passou durante esse intervalo de tempo? A hipótese que eu gostaria de defender é que ele leu os Princípios de Psicologia que William James publicou em 1890, primeiro livro de psicologia funcional que já anuncia o seu pragmatismo como uma teoria naturalista do conhecimento.

\section{COMUNICAÇÃO, AÇÃO, COOPERAÇÃO}

\subsection{Vida prática, vida social, vida comum $\left(\mathrm{DI}^{4}\right)$}

A noção de vida prática intervém desde as primeiras linhas do Ensaio:

Exprimimo-nos necessariamente por palavras, e pensamos mais frequentemente no espaço. Em outros termos, a linguagem exige que estabeleçamos entre nossas ideias as mesmas distinções claras e precisas, a mesma descontinuidade que a dos objetos materiais. Essa assimilação é útil na vida prática, e necessária na maior parte das ciências.

Portanto, a vida prática não é primeira, mas segunda em relação à linguagem e ao espaço, que são como suas condições de possibilidade. Isso é verdadeiro ao menos para a vida prática humana, visto que Bergson sugere que os animais têm uma relação com o mundo que não passa pela concepção de um espaço (BERGSON, 2007, p. 71-72) - este que é entendido, lembremos, como um meio homogêneo no qual se pode justapor uma multitude 
de objetos quaisquer, cada um dos quais ocupando posições distintas em relação às demais. Sem dúvida, é por isso que Bergson julga o espaço e a linguagem como úteis, mas não como necessários, à vida prática. Já há aqui, portanto, uma concepção naturalista da vida prática, mas que ainda não está desenvolvida por ela mesma: a emergência da ideia de espaço, antes mesmo da aparição da linguagem, permitiria passar de uma vida prática animal, na qual o indivíduo ainda não se distingue inteiramente do mundo exterior e nem distingue os objetos externos uns dos outros (BERGSON,2007,p. 177), a uma vida prática propriamente humana. Tese extremamente surpreendente, do homem que teria primeiramente inventado os fundamentos da geometria (ideia de um espaço formal sem conteúdo sensível onde os elementos apenas se distinguem pelas suas posições) antes de inventar a linguagem e objetivar o mundo exterior. Pois Bergson faz da concepção de um tal espaço a condição de possibilidade da existência do mundo exterior e da linguagem, os quais estão no fundamento da vida prática humana. Ele aceita de Kant a definição segundo a qual o espaço é uma forma da nossa sensibilidade, na medida em que ela é justamente, aos seus olhos, a condição formal de nossa percepção do mundo exterior. Sem esta faculdade de distinguir e justapor termos em geral (termos quaisquer), nós não poderíamos perceber objetos materiais concretos e particulares, tanto na sua exterioridade em relação a nós mesmos como na exterioridade de uns em relação aos outros. Eles vincular-se-iam todos uns aos outros e a nós mesmos numa vaga continuidade vivida. Portanto, é a noção mesma de "objeto" que pode emergir com o espaço. A linguagem irá ao mesmo tempo beneficiar-se da descontinuidade, assim operada por nosso pensamento espacializante no mundo vivido, quanto reforçá-la, estabilizando a identidade distinta desses objetos ao nomeá-los com diferentes termos.

Mas se a espacialização é primeira em relação aos fundamentos da vida prática, mundo exterior e linguagem, é justamente a vida prática que dá ao processo uma finalidade e sua razão de ser. Se o homem passa a impor uma tal forma nas suas relações com o mundo, isso não é "por nada, por prazer”, mas porque é "útil”, como o dizia o prefácio. Ele deve, portanto, tirar disso um benefício: a vida prática deve tornar-se mais fácil. Mal qual é esse ganho em relação à vida animal? A resposta não deixa de surpreender o leitor familiar de Bergson pois Bergson não diz em lugar algum do Ensaio que o estabelecimento de tal forma facilita nossa ação sobre os objetos externos, e que a sua utilidade prática reside, portanto, na vantagem que ela nos proporciona no controle de nosso ambiente. Na realidade, no Ensaio, não se trata nunca de ação, no sentido da interação do indivíduo com o seu ambiente, e o conceito de ação, quando aparece, está inteiramente absorvido pelo problema do ato livre que Bergson de modo algum coloca nesses termos. A resposta de Bergson é antes a de que o estabelecimento de uma tal forma tem como destinação prática "a facilidade das relações sociais" (BERGSON, 2007, p. 126): é a vida social, portanto, que com isso é tornada mais cômoda. Resposta surpreendente, não somente porque "prático" perde aqui sua referência direta à ação, mas igualmente porque o salto do espacial ao social parece bem perigoso! O operador que permite a Bergson transpor um tal fosso é o conceito de "comum" que, segundo ele, basta para qualificar algo como "social".

A linguagem é comum porque a maior parte das palavras utilizadas são gerais. Que uma palavra seja geral significa, primeiramente, que ela é comum a vários objetos significados, "coelho" valendo para toda uma série de objetos externos distinguidos que apresentam traços comuns. Mas essa generalidade igualmente lhe permite ser comum a vários sujeitos falantes: um sujeito A poderá, assim, comunicar ao sujeito B o menu do jantar servindo-se da palavra como o menor denominador comum entre o coelho único e original que ele está em vias de cozinhar e os coelhos que B encontrou na sua vida. Sendo comum ao novo objeto que B não conhece e aos objetos que ele já conhece, a palavra é, portanto, por natureza, social, se social é o que não é pessoal, mas comum a várias pessoas. Não há, pois, linguagem privada.

Ainda mais impressionante, o mundo dos objetos externos é, para Bergson, um mundo comum:

A intuição de um espaço homogêneo já é um encaminhamento para a vida social. O animal provavelmente não se representa, como nós, além de suas sensações, um mundo exterior bem distinto dele que seja a propriedade comum 
de todos os seres conscientes. A tendência em virtude da qual nós figuramos claramente essa exterioridade das coisas e essa homogeneidade de seu meio é a mesma que nos leva a viver em comum e a falar (BERGSON, 2007, p. $102-103$, n.s.)

Essa passagem subentende que os animais são idealistas solipsistas por natureza: sem sair de suas sensações, cada um deles vive no pequeno mundo privado da sua experiência subjetiva. A dissociação da sensação e do objeto sentido que, como toda dissociação, é tornada possível pela aplicação do esquema espacial, permite ao homem diferenciar o mundo subjetivo de suas sensações e o mundo exterior dos objetos sentidos. Desse modo, o mundo dos objetos é necessariamente um mundo público, partilhado, pois os objetos externos, na medida em que foram exteriorizados, não pertencem mais a ninguém. Os objetos externos são, portanto, sociais por natureza, pois participam de direito do "domínio comum": "um mundo exterior bem distinto de nós e na percepção do qual todas as inteligências entram em comunhão” (BERGSON, 2007, p. 177).

Enfim, temos igualmente todo o interesse em esquecer a nossa personalidade subjetiva singular se queremos facilitar as relações sociais, e é essa também a razão pela qual, segundo Bergson, tratamos nossa vida interior com base no modelo do mundo exterior, aplicando - indevidamente - o esquema espacial de divisão e justaposição ao fluxo contínuo de nossa consciência. É nesse ponto que melhor se apreende a finalidade social do pensamento espacial. Com efeito, pode-se compreender que espacializamos a extensão concreta e que nela recortamos objetos exteriores: a matéria aqui não é completamente estranha à forma que se impõe a ela. Mas, por que espacializar isto que resiste e que é mesmo contrário a toda distinção e justaposição, a saber, a vida interior que escoa na duração? Somente duas respostas são possíveis: ou somos perversos - e às vezes é assim que Bergson fala quando ele evoca nossa "obsessão" (BERGSON, 2007, p. 168) pela ideia de espaço ou quando descreve a consciência como sendo "atormentada por um insaciável desejo de distinguir" (BERGSON, 2007, pg. 95); ou temos interesse em fazê-lo porque ganhamos com isso alguma coisa que compensa as eventuais perdas. $\mathrm{O}$ sucesso de nossa espacialização do mundo exterior em termos de relações sociais nos convida a espacializar o que for possível de nossa vida interior. A comunicação de estados internos e pessoais, puramente privados, torna-se então possível graças à sua tradução na linguagem pública apropriável por todos, e a participação na vida social é com isso facilitada: "quando se trata de nossos estados de consciência, temos todo o interesse em entreter a ilusão pela qual os fazemos participar da exterioridade recíproca das coisas exteriores, porque essa distinção e, ao mesmo tempo, essa solidificação, nos permitem dar a eles nomes estáveis, apesar de sua instabilidade, e distintos, apesar de sua penetração mútua. Elas nos permitem objetivá-los, fazêe-los entrar, de algum modo,

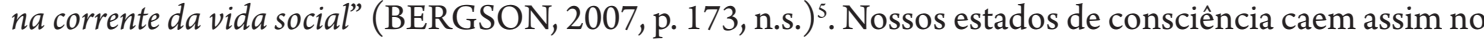
"domínio público" (BERGSON, 2007, p. 124), pois retivemos apenas seus aspectos comuns e, portanto, comunicáveis, "o resíduo por conseguinte impessoal das impressões sofridas, em um determinado caso, pela sociedade inteira" (BERGSON, 2007, p. 99). Disso resulta um eu social que constitui um misto de consciência e de objeto, de dentro e de fora, de privado e de público: um eu que não é inteiramente eu, mesmo se ele tampouco é um completo outro, um eu situado "na superfície de comunicação" com o mundo exterior. Para reencontrar-se, seria preciso então se isolar de todo contato com outrem, fechar os olhos ao mundo exterior, até mesmo abster-se de falar internamente; enfim, não mais procurar separar e justapor o que nos fosse dado...

Ao fim do livro, a noção de "vida prática" permanece cheia de ambiguidades. Certamente, há um princípio utilitarista em obra na espacialização, dado que há um ganho prático, mas não há um princípio pragmatista no sentido estrito, na medida em que a sua diferença prática não está em uma ação mais adaptada, mas em relações sociais facilitadas ${ }^{6}$. Além disso, a vida social, suposta como finalidade do conjunto do processo, é uma categoria muito pobre: não há história, instituições e regras nesse mundo comum, apenas objetos e palavras. Será preciso esperar o último livro de Bergson para que esse ponto seja precisado. Mas, no Ensaio, 
"vida social" é uma categoria essencialmente delimitada por negação: é social tudo o que não é interior e pessoal. Além disso, a função da linguagem permanece ela mesma indeterminada: espacializa-se para se comunicar melhor, mas para que serve se comunicar melhor? Em que facilitar as relações sociais através de um compartilhamento do mundo é um fim em si? É somente para se ter o prazer de falar em conjunto e comunicar os estados da alma que uma tal ordenação do mundo é feita? Por fim, surge uma discordância entre a vida prática e a ciência. Pois Bergson não diz que a ciência apareceu, após a espacialização que é a sua condição necessária, para facilitar as relações sociais. Desde o Ensaio, Bergson sustenta que "a ciência tem como principal objetivo prever e medir" (BERGSON, 2007, p. 173), o que subentende uma concepção instrumentalista da ciência, que não estaria aí para representar a realidade nela mesma, mas para nos ajudar a prever e, portanto, antecipar o curso futuro da experiência. Essa concepção instrumentalista da ciência é inteiramente concordante com o pragmatismo, mas ela é estranha ao utilitarismo social que percorre todo o livro. O sentido comum da vida prática e da ciência ainda não estão alinhados.

\subsection{A virada pragmática $(M M)$}

Sete anos mais tarde, a "vida prática" ganha um sentido pragmatista, e a maior parte das ambiguidades que acabamos de sublinhar são superadas. É que, do espacial ao social, faltava um elo que o "comum" não podia substituir: o vital. De agora em diante, "vida prática" ganha um sentido antes biológico do que social, que Bergson não virá mais a modificar. Viver significa agir (BERGSON, 2008a, p. 221) e, doravante, são "as necessidades fundamentais da vida" (BERGSON, 2008a, p. 222) que dão uma finalidade ao conjunto das operações do espírito sobre o mundo exterior. Todas essas necessidades estão de tal modo relacionadas com "a conservação do indivíduo ou da espécie" (BERGSON, 2008a, p. 222), que a passagem da vida prática animal à vida prática humana significa, graças ao desenvolvimento do cérebro, um aumento da capacidade de "buscar ou fugir" (BERGSON, 2008a, p. 222) dos corpos independentes do seu próprio corpo; portanto, de uma melhor possibilidade de conservação. Em suma, na expressão "vida prática", "vida" doravante remete às necessidades de conservação do organismo, e "prático" às maneiras de agir úteis a esta conservação ${ }^{7}$. A conservação substituiu a conversação como objetivo prático da divisão do real. Testemunho dessa passagem, o prefácio da primeira edição de Matéria e Memória faz eco àquele do Ensaio que citamos no começo: em $M M$, também se trata sempre de "liberar a vida interior dos símbolos praticamente úteis que a recobrem" (BERGSON, 2008a, p. 445), mas, desta vez, trata-se de fazê-lo "delimitando (...) minuciosamente a ação e o conhecimento" (BERGSON, 2008a, p. 444), pois se as "dificuldades metafísicas" nascem "de nossa mistura da especulação e da vida prática” (BERGSON, 2008a, p. 444), é preciso a partir de então entender essa última como o conjunto dos "hábitos contraídos na ação".

As grandes etapas do processo de dissociação da continuidade exterior e interior que Bergson havia desenvolvido em $D I$ são então retomadas em $M M$ e definidas em termos de ação em função dessa nova orientação pragmatista. O primeiro capítulo nos ensina que a organização da matéria em objetos externos bem recortados e destacados do restante do quadro responde às exigências da vida corporal, a percepção mesma que deles temos sendo estruturada pela "ação possível de meu corpo sobre eles" (BERGSON, 2008a, p. 16). O mundo dos objetos externos é, portanto, menos o mundo comum do que o mundo das interações entre os corpos. Os dois capítulos seguintes, em seu exame das dificuldades da memória de palavras, são uma primeira ocasião para afirmar que "todo signo é orientado em relação à prática, à ação", que ele é "um convite à ação" (BERGSON, 2002, p. 52). Um doente que sofre de surdez verbal não compreende mais o que lhe é dito: aos olhos de Bergson, isso mostra que somente se pode compreender o que nos é dito se se repete em voz baixa a palavra ouvida - seja essa repetição uma ação real ou apenas nascente. A comunicação social está, portanto, fundada sobre a capacidade de reagir - não há escuta puramente passiva e desinteressada. Finalmente, o quarto e último capítulo pode retornar a isto que era o 
mais profundo em $D I$, a saber, a ideia de espaço que tornava possível o mundo exterior e a linguagem. É bem lembrado que o espírito "traça divisões na continuidade da extensão", pois ele cede "às sugestões do necessário e às necessidades da vida prática" (BERGSON, 2008a, p. 235). Mas, novamente, "vida prática" significa aqui as possibilidades de ação que uma tal divisão da extensão vivida fornece ao homem, a ponto de o espaço homogêneo - como, por outro lado, o tempo espacializado - passar então a ser definido como o "esquema de nossa ação sobre a matéria" (BERGSON, 2008a, p. 237). Espacializa-se para poder agir ou, antes, para poder aumentar e melhorar as nossas capacidades de ação sobre a matéria: o interesse que dá uma finalidade a essa operação não é mais social, mas "vital” (BERGSON, 2008a, p. 238).

Uma ilustração suplementar dessa virada pragmática pode ser vista em um ponto mais preciso: a análise comparada da crítica ao associacionismo em DI e MM. Por que o psicólogo associacionista se engana em DI? Porque ele substitui a experiência singular e pessoal por um signo desta que, por sua generalidade, é comunicável. "Assim que respiro o odor de uma rosa, lembranças confusas da infância retornam à memória" (BERGSON, 2007, p. 121). O associacionista considera que o estado de consciência A (o odor da rosa) sugeriu ao espírito o estado de consciência B (uma lembrança de infância, por exemplo, uma babá), a transição de um ao outro explicando-se pela contiguidade (a babá possuía um perfume de rosas) e pela semelhança (o odor presente assemelha-se ao odor do perfume de outrora): o odor presente evoca o odor passado (que se assemelha a ele), que evoca a imagem da babá (por contiguidade). Mas o associacionista não conservou do odor da rosa presente senão o "que pertence ao domínio comum" (BERGSON, 2007, p. 122), isto é, apenas um odor impessoal, recoberto pela palavra "rosa", para as comodidades da comunicação. Na realidade, sustenta Bergson, o odor da rosa que eu sinto no momento presente é absolutamente único e singular, insubstituível, pois ele não está dissociado, na experiência que dele tenho, da lembrança da babá e de seu perfume. Não há aqui três estados de consciência religados entre si por associações exteriores, mas um só todo, único e indivisível: uma percepção que possui sua nuance própria devido à lembrança de infância que a penetra. Esse odor, tal como ele é realmente sentido, é, portanto, único em seu gênero e, por conseguinte, inefável: não há quem possa realmente conhecê-lo senão eu. Mas, para as necessidades da vida social, nós somente retemos o menor denominador comum das experiências "do mesmo gênero" e o chamamos "odor de rosa". O que é útil para a vida social é entretanto prejudicial ao conhecimento, e a psicologia, que deveria se colocar nesse último ponto de vista, comete um erro ao aceitar os objetos produzidos pelo senso comum no lugar dos dados imediatos da consciência. Ao invés de se colocar em um ponto de vista puramente teórico, o psicólogo associacionista permaneceu sob a dependência do ponto de vista prático do sentido comum - ele continua falando quando seria preciso pensar.

Mas qual erro ele comete em $M M$ ? Quase o contrário: ele projetou o seu ponto de vista de sábio desinteressado e sonhador no seu objeto que é prático, cedendo assim ao sofisma intelectualista. É que a prática mudou de sentido e significa ação útil. Uma criança vê uma vela, estende a mão e se queima. Na outra vez em que ela vê uma vela, ela inibe o movimento instintivo de preensão. $\mathrm{O}$ cenário explicativo faz apelo às associações: o espírito da criança apreende na segunda situação o que se assemelha à situação anterior (a visão da chama presente desperta a lembrança da chama passada: associação por semelhança); depois, o espírito da criança aproxima à situação presente o que se seguiu em sua experiência passada (a saber, toda a sequência: a visão da chama - preensão pela mão - dor - retração da mão: associações por contiguidade). Cada um dos dois tipos de associação tem, portanto, a sua função específica necessária para determinar a reação: a primeira está encarregada do reconhecimento, isto é, da identificação da excitação presente (por semelhança a uma excitação passada); a segunda, da rememoração da sequência passada (com vistas à previsão das consequências possíveis da situação presente). As duas relações associativas permitem, assim, a substituição de uma reação reflexa mal ajustada por uma reação adquirida mais adaptada, aumentando com isso as chances de conservação do indivíduo. Com efeito, nenhuma outra relação, senão a semelhança 
e a contiguidade, pode explicar melhor por qual mecanismo um organismo pode beneficiar-se de sua experiência passada para reagir melhor a situação presente: "essas não são formas contingentes de nossa vida psicológica" (BERGSON, 2008a, p. 186, n.s.). O erro do psicólogo associacionista é, portanto, pensar que se associa "por nada, por prazer", e não para obter uma melhor reação. Um tal erro de ponto de vista tem como consequência malograr na explicação da razão de ser da contiguidade e da semelhança: por que essas duas relações e não outras? Além disso, o seu ponto de vista intelectualista priva-o de uma verdadeira explicação do processo psicológico, na medida em que a seleção desta lembrança antes de outra é arbitrária se essas duas associações não têm uma função vital. Por que esta lembrança é invocada antes de outra? Em si, sempre se poderá encontrar entre dois estados de consciência quaisquer semelhanças e mesmo quaisquer contiguidades - é assim no sonho, onde qualquer estado de consciência, desligado das urgências da ação, pode associar-se livremente a qualquer outro estado, pois "as necessidades da vida não estão mais aí para regular o efeito da semelhança e, consequentemente, da contiguidade" (BERGSON, 2008a, p. 187).

Assim como há pouco a explicação associacionista aplicava-se bem a uma parte da vida consciente, mas apenas à sua superfície social voltada para o exterior e não às profundezas da consciência pessoal, da mesma maneira, no presente, ela ainda dá conta de uma parte da vida consciente, mas apenas da vida profunda do sonho desligado da ação, e não de seu esforço de atenção à vida. Nos dois casos há erro, pois o psicólogo transfere a sua própria situação ao fenômeno que ele deve explicar. Mas, no primeiro caso, é porque o psicólogo é um homem prático vivendo numa cidade e utilizando as palavras de todo mundo que ele comete esse abuso; no segundo caso, ao contrário, é porque ele é um sábio desinteressado vivendo em seu laboratório e desligado das urgências da vida prática.

\subsection{O trabalho humano (EC, PM)}

O espaço, a percepção dos objetos exteriores, a linguagem: tudo isso que, no Ensaio, devia participar na facilitação da vida social está, a partir de agora, orientado para o melhoramento da ação. Mas o que então é a vida social ela mesma? As menções sobre a "vida social" eram pouco numerosas e bastante discretas em $M M$, e sempre feitas em referência às conclusões do Ensaio. É a partir de Evolução Criadora (BERGSON, 2008b) que Bergson retoma a questão e se decide definitivamente em favor do primado da ação biológica sobre as relações sociais, na medida em que a linha dos fatos da evolução converge com aquela da psicofisiologia abordada precedentemente para mostrar que "somos feitos para agir tanto ou mais do que o somos para pensar; ou antes, quando seguimos o movimento da nossa natureza, é para agir que pensamos" (BERGSON, 2008b, p. 296). E a linguagem e as relações sociais, das quais falava DI, são agora retomadas do ponto de vista pragmatista imposto por $M M$ :

Enumeramos alguns dos traços essenciais da inteligência humana. Mas tomamos o indivíduo em estado isolado, sem ter em conta a vida social. Na realidade, o homem é um ser que vive em sociedade. Se é verdade que a inteligência humana visa a fabricar, é preciso acrescentar que ela se associa, para isso como para o resto, a outras inteligências. Ora, é difícil imaginar uma sociedade cujos membros não se comunicam entre si por signos. Sem dúvida as sociedades de insetos têm uma linguagem e, como a do homem, essa linguagem deve estar adaptada às necessidades da vida comum. Faz com que uma ação comum se torne possível. (BERGSON, 2008b, p. 158)

O alinhamento e a finalidade dos diferentes termos constitutivos da vida prática estão doravante esclarecidos: a linguagem é feita para facilitar as relações sociais que são feitas para facilitar e elevar a potência da ação humana. Se a evolução chega na vida social humana, é que a sociedade permite "um compartilhamento das energias individuais" (BERGSON, 2009a, p. 26), isto é, um maior controle da matéria. O "comum", que era o operador que permitia passar do espacial ao social no primeiro livro, passa doravante a qualificar a ação: é a ação que é comum, e que, em troca, faz desse mundo um mundo comum. A vida social participa 
da vida prática, não apenas porque ela constitui um mundo comum de palavras e objetos, mas porque esse "compartilhamento" é um meio suplementar de melhorar a interação dos homens com o seu ambiente, em uma palavra, com a sua vida material.

O olhar retrospectivo das duas introduções de 1922 reunidas em O Pensamento e o movente (BERGSON, 2009b) concluirá este movimento de subordinação do social ao vital. Se o texto ainda oscila repetidas vezes, invocando tanto as exigências da vida social quanto as urgências da ação vital como razão final para se dissociar e estabilizar a realidade, se por vezes chega a justapô-las sem conceder um primado a uma ou à outra (BERGSON, 2009b, p. 58 ou p. 64), definitivamente termina por se decidir em duas passagens muito importantes (BERGSON, 2009b, p. 73-74 e p. 86-87), das quais citaremos apenas o momento mais explícito:

\footnotetext{
É tão natural ao homem falar quanto andar. Ora, qual é a função primitiva da linguagem? É a de estabelecer uma comunicação com vistas a uma cooperação. A língua transmite ordens ou avisos. Ela prescreve ou descreve. No primeiro caso, é o apelo à ação imediata; no segundo, é a descrição da coisa ou de alguma de suas propriedades com vistas a uma ação futura. Mas, num caso como no outro, a função é industrial, comercial, militar, sempre social. As coisas que a linguagem descreve foram recortadas no real pela percepção humana tendo-se em vista o trabalho humano (BERGSON, 2009b, p. 86-87, n.s.)
}

É a noção de "trabalho humano", entendido como "cooperação", que passa a integrar a "comunicação" da qual falava $D I$ e a "ação" da qual falava $M M^{8}$. A linguagem e as relações sociais, cujas estruturas nos homens não estão fixadas para lhes dar maior adaptabilidade, não estão portanto aí "por nada, por prazer", mas para organizar a ação dos indivíduos, para deles extrair uma eficiência maior pela integração dos corpos. Quando digo: "o coelho está em sua toca", eu não estou apenas descrevendo um estado de coisas dado, eu convoco os demais para transformar a situação através de um chamado à ação comum. A forma lógica desse enunciado tem, na realidade, uma função prática: "ao anunciar o sujeito ["o coelho"], apoiamos nossa comunicação em um conhecimento que nossos interlocutores já possuem, uma vez que a substância é suposta como invariável; a partir de então, eles sabem para qual ponto dirigir a sua atenção; virá então aquilo sobre o que queremos informá-los, na espera do qual os deixávamos ao introduzir a substância [espera aberta pela cópula “...está..."], e que o atributo aporta ["em sua toca"] (BERGSON, 2009b, p. 74). Meus companheiros de caça sabem então o que fazer, e uma ação comum pode ser organizada com maior chance de sucesso e, portanto, de conservação do grupo - que comerá esta noite. Portanto, não há apenas os enunciados performativos, mas igualmente os constatativos, que são "transformativos" na medida em que eles igualmente encontram seu sentido e seu valor nas consequências práticas que se seguem deles sob a forma de um trabalho a se fazer, ou seja, de uma transformação da matéria, que a faz passar de um estado de coisas dado, de fato afetado, a um estado de coisas desejado. Em Bergson, sintaxe e semântica estão subordinadas à pragmática.

Bem antes de As duas fontes (Bergson, 2008c), a vida social está, portanto, compreendida no horizonte da vida. De fato, pode-se sustentar que, desde Evolução criadora, a análise da linguagem como instituição social respondendo a um fim vital permitia pressagiar a posição naturalista de Bergson sobre a questão. Finalmente, Bergson pôde espessar seu conceito de vida social - tão pobre em DI - precisamente porque ele soube repensá-la a partir das práticas, como testemunha a passagem da comunicação à ação e, depois, à cooperação.

\section{PRAGMATISMO E PSICOLOGIA FUNCIONAL}

Esse percurso da obra terá assim mostrado a virada que constitui Matéria e Memória, a correção que essa obra aporta à precedente - correção não no sentido de refutação, mas de retoque e aprofundamento -, permitindo superar as ambiguidades que foram aqui assinaladas. Como explicar essa virada que nada na conclusão de DI permitia pressagiar? Minha hipótese é a de que Bergson se aproveitou da leitura dos 
Principles of Psychology, (JAMES, 1981) de William James, que aparecem um ano após DI e são um imediato sucesso internacional. Bem antes da psicologia da conduta ou do comportamento, James propõe ali uma psicologia da reação que anunciava seu pragmatismo. É certo que a obra é citada em $M M$, mas sobre pontos precisos, não pela sua inspiração como um todo. Entretanto, é justamente a imagem global da psicologia que muda de $D I$ a $M M$, que não deixa de ver nela uma ciência natural.

\subsection{O primado da reação de James a Bergson}

É impressionante constatar não apenas a inspiração pragmática de conjunto, vivida por Bergson, que doravante toma como fio condutor da psicologia "o caráter utilitário das funções mentais, essencialmente voltadas à ação" (BERGSON, 2008a, Prefácio à 7a ed., p. 9), mas igualmente as convergências de detalhe quando se compara o primeiro capítulo de $M M$ com o segundo capítulo dos Principles, intitulado "As funções do cérebro". Nesse capítulo se encontra, com efeito, a base fisiológica tanto da psicologia funcional como da filosofia pragmatista. Pode-se sustentar que a psicologia pragmática ou funcional encontra sua condição de possibilidade epistemológica na análise da fisiologia da ação reflexa, presente ao longo de todo o século XIX, e que chega a fazer da ação reflexa o comportamento elementar em relação ao qual todos os outros comportamentos não são senão complicações ${ }^{10}$. Deste modo, todo comportamento, por mais complicado que seja, compreenderá, de um ponto de vista orgânico, assim como o menor arco reflexo, três fases - a fase de recepção sensorial, a fase de reorientação central da corrente nervosa, a fase de reação motora ou glandular - e terá como finalidade a terceira dessas fases; a impressão sensorial e a reflexão nos centros nervosos existem para a reação. Quando o cérebro intervém na determinação do comportamento, é a título de fase intermediária ou mediadora. Por conseguinte, as funções psicológicas que encontram a sua condição fisiológica na atividade cerebral sempre intervêm após uma sensação e visando determinar uma reação que seja uma resposta ajustada à excitação inicial.

Bergson retoma essa análise de James, ainda que ele marque a sua diferença com o dualismo afirmado entre a função cerebral e a função propriamente psicológica. Eis uma lista das impressionantes similaridades entre os dois capítulos:

\begin{tabular}{|c|c|}
\hline $\begin{array}{l}\text { James, Principles of Psychology (1890) } \\
\text { Cap. } 2 \text { "As funções do cérebro" }\end{array}$ & $\begin{array}{c}\text { Bergson, Matéria e Memória (1896) } \\
\text { I. "Da seleção das imagens } \\
\text { pelo corpo" }\end{array}$ \\
\hline $\begin{array}{l}\text { 1. Afirmação da continuidade do eixo cérebro-espinhal } \\
\text { (diferença de grau) } \\
\text { Essa continuidade permite que se analise a estrutura e a função do } \\
\text { cérebro de maneira análoga àquela da medula espinhal, centro nervoso } \\
\text { da ação reflexa: }\end{array}$ & $\begin{array}{l}\text { "Portanto, não há senão uma diferença de } \\
\text { grau, não pode haver aí uma diferença de } \\
\text { natureza entre a faculdade dita perceptiva } \\
\text { do cérebro e as funções reflexas da medula } \\
\text { espinhal" (BERGSON, 2008a, p. 19) }\end{array}$ \\
\hline $\begin{array}{l}\text { "Nos dois lugares, a corrente descarrega-se nos músculos somente } \\
\text { depois de ter entrado. Porém, enquanto que o caminho pelo qual ela } \\
\text { se descarrega é determinado nos centros inferiores por reflexos pouco } \\
\text { numerosos e previamente fixados em arranjos celulares, nos hemisférios } \\
\text { eles são numerosos e instáveis. Compreender-se-á que se trata, portanto, } \\
\text { apenas de uma diferença de grau e não de natureza, e que isso não muda } \\
\text { o tipo de reflexo. Que toda ação seja conforme a esse tipo é a concepção } \\
\text { fundamental da fisiologia nervosa contemporânea" (JAMES, 1981, p. 35) }\end{array}$ & $\begin{array}{l}\text { "Mas basta que se compare a estrutura } \\
\text { do cérebro àquela da medula para se } \\
\text { convencer de que há apenas uma diferença } \\
\text { de complicação, e não uma diferença de } \\
\text { natureza, entre as funções do cérebro e a } \\
\text { atividade reflexa da medula" (BERGSON, } \\
\text { 2008a, p. 25) }\end{array}$ \\
\hline
\end{tabular}




\section{Esquema triádico e orientado do comportamento complexo}

Disso resulta que o comportamento complexo, fazendo intervir os hemisférios cerebrais mesmo que diferindo do comportamento puramente reflexo, é igualmente analisado em três fases e orientado com vistas à reação: todo comportamento é, portanto, sensório-motor:

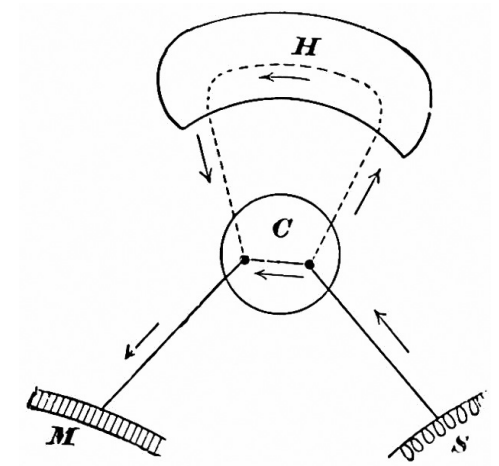

"Caso se compare a corrente nervosa com uma corrente elétrica, o sistema nervoso C, sob os hemisférios, é semelhante a um circuito direto que vai dos órgãos sensoriais ao músculo ao longo da linha S-C-M da figura 2 (JAMES, 1981, p. 21). Os hemisférios $\mathrm{H}$ acrescentam o longo circuito ou a volta através da qual a corrente pode passar se, por uma razão qualquer, a linha direta não é utilizada” (JAMES,1981, p. 33)

[S: receptor sensorial; C: centro nervoso da medula; $\mathrm{H}$ : hemisférios; M: efetor motor]

\section{Depreensão da função específica do cérebro}

O cérebro retém a lembrança dos comportamentos anteriores (James) ou ativa essas lembranças (Bergson) de tal maneira que uma certa escolha pode, doravante, ser oferecida entre várias possibilidades de reações, e em particular a possibilidade de substituir reações inatas por reações adquiridas, o que James chama de "a educação dos hemisférios" (cf. o exemplo da substituição do reflexo de preensão pelo gesto de retração diante de uma vela). O cérebro é, portanto, uma condição material da indeterminação da ação, isto é, da liberdade dos seres viventes:

"Se damos o nome de "parceiros" aos membros dos pares originais de impressão e de movimento reflexo, nós podemos dizer que a função dos hemisférios é simplesmente a de fazer trocas entre os parceiros. $\mathrm{O}$ movimento $m n$, que é de nascimento o parceiro da sensação $s n$, torna-se pelo intermédio dos hemisférios o parceiro da sensação $s 1$, s2 ou s3. É como o grande quadro de distribuição de uma central de telefonia. Nenhum novo processo elementar está implicado, nem nenhuma impressão ou movimento próprio aos hemisférios, mas apenas um número de combinações impossíveis no nível da maquinaria inferior tomada isoladamente, e um aumento indefinido das possibilidades de comportamento da parte da criatura." (JAMES, 1981, p. 38) 
A importância da ação reflexa para a psicologia já havia sido notada antes de James, mas sua originalidade está em ter feito dela o fio condutor para a análise psicológica de todas as funções mentais. Percepção, associação, concepção, raciocínio: todas essas funções intelectuais não têm por objetivo elaborar conhecimentos pelo simples prazer de fazê-lo, mas chegar a uma reação que seja mais inteligente que a ação instintiva ou habitual, isto é, que favoreça uma melhor conservação do indivíduo ou da espécie: "a corrente de vida que entra pelos nossos olhos ou nossas orelhas está destinada a sair pelas nossas mãos, nossos pés ou nossos lábios” (JAMES, 1979, p. 92). O que James chama de "intelectualismo" é precisamente, em primeiro lugar, um engano quanto ao caráter instrumental das funções intelectuais: a inteligência em geral, cuja intervenção se situa entre uma excitação do mundo exterior sobre nós e a nossa reação em troca a esta excitação, não tem por fim a especulação, mas a ação. O homem é antes de tudo um ser vivente, no qual a capacidade de pensar confere uma vantagem vital.

\subsection{Bergson funcionalista}

Essa concepção sensório-motora do espírito, interpretada de um ponto de vista darwiniano mais geral, está na origem da "psicologia funcional”, corrente que aparece oficialmente no início do século XX nos Estados Unidos entre os discípulos de James e que busca sistematizar essa penetrante obra, em particular James R. Angell, aluno de James e colega de Dewey e Mead em Chicago (ANGELL, 1907, p. 61-91). A originalidade desse novo ponto de vista funcional está sobretudo em dois pontos que Angell explicita em seu manifesto de 1907. Primeiramente, o funcionalismo não estuda mais os conteúdos mentais, mas as operações mentais: assim, ele não se ocupa com aquilo que o espírito é, mas com aquilo que ele faz. Desse modo, ele passa de uma abordagem estática a uma abordagem dinâmica, e substitui a atitude analítica e descritiva por um esforço de explicitação que busca compreender o funcionamento (how) e a razão de ser $(w h y)$ dos fenômenos mentais. Essa razão de ser, em segundo lugar, ele a encontra na biologia de inspiração darwiniana: ele adota o "ponto de vista biológico". A lição fundamental que a psicologia tira do darwinismo é que as estruturas orgânicas possuem suas características atuais em virtude da eficácia com a qual elas permitem ao organismo se adaptar às condições de vida de seu ambiente. O postulado de base da psicologia funcional se segue logicamente disso: o espírito permite melhorar esse ajustamento do organismo com o seu ambiente, segundo as diversas modalidades que constituem outras tantas grandes funções psicológicas. Cabe portanto ao psicólogo encontrar quais são as funções especiais do espírito, cuja classificação substituirá aquela das antigas faculdades, uma vez que cada faculdade será definida pela sua operação e função próprias, e não mais pela sua estrutura. Em um ambiente onde as diferenças entre cores, tamanhos e formas dos objetos não seriam úteis para a segurança e prosperidade de um organismo, a atenção não teria uma função discriminadora. Em um mundo sem semelhanças, não haveria uma faculdade de conceber ideias gerais. Em um mundo sem uniformidade, não haveria hábitos. As faculdades se diferenciam assim pelas suas funções, isto é, pelas diferentes vantagens que elas conferem ao organismo na sua relação com o ambiente: até que uma tal vantagem não tenha sido desenvolvida, a faculdade estudada não está justificada e não pode remeter senão a uma ilusão do psicólogo.

Ora, é certamente um psicólogo funcional que pode escrever estas linhas em 1922:

No labirinto dos atos, estados e faculdades do espírito, o fio que jamais se deveria soltar é aquele que fornece a biologia. Primum vivere. Memória, imaginação, concepção, percepção e, enfim, generalização, não estão aí "por nada, por prazer". Em verdade, parece que o espírito, no entendimento de certos teóricos, tenha caído do céu com uma subdivisão de funções psicológicas cuja existência é apenas o que há para se constatar: dado que essas funções são tais, elas seriam utilizadas de tal maneira. Acreditamos, ao contrário, que é porque elas são úteis, porque são necessárias para a vida, que elas são o que são: é preciso referir-se às exigências fundamentais da vida para explicar a sua presença e, se for necessário, justificá-la, quero dizer: saber se a subdivisão ordinária nestas ou naquelas faculdades é artificial ou natural, por conseguinte, se devemos mantê-la ou modificá-la. (BERGSON, 2009b, p. 54) $)^{12}$ 
Pode-se assim considerar metade de Matéria e Memória como um tratado de psicologia funcional que "tem por objeto o estudo do espírito humano enquanto funcionando utilmente para a prática" (BERGSON, 2008a, p. 8) - a outra metade ocupada pela metafísica, como um esforço para se emancipar de um tal ponto de vista funcionalista a fim de apreender o espírito antes dessa virada prática em que ele devém humano demasiado humano. Poder-se-ia mesmo considerar extrair, do curso do conjunto de sua demonstração, as análises funcionais que Bergson faz de tal ou qual faculdade, de modo a condensar cada uma em um capítulo do Compêndio do perfeito funcionalista menor: percepção no primeiro capítulo (que se desdobra em um princípio de seleção e interesse - princípio cardinal em James); atenção e memória no fenômeno de reconhecimento, no segundo capítulo; ideias gerais e associação, no terceiro que, como vimos, são todas definidas em função da vantagem conferida ao corpo para utilmente reagir às solicitações de seu ambiente que, nos melhores funcionalistas, é tanto social quanto natural. Mais tarde, poder-se-á completar a lista com um capítulo sobre o instinto ou a função fabuladora...

Não se deve ignorar que Bergson de direito limita essa psicologia nas suas ambições de compreender o espírito: ela somente compreende do espírito seu papel na conservação e na prosperidade do organismo. Ela não nos permite compreender o que ele é em si mesmo, mas apenas para que serve, isto é, em que ele é útil ao corpo. Bergson reintroduz assim a ideia de uma natureza do espírito para além de sua função. Ora, para conhecer o espírito tal como ele é nele mesmo, em sua realidade espiritual, não é mais à anatomia, à fisiologia ou à biologia que é preciso se voltar, mas primeiramente à introspecção, ou melhor, a um uso renovado da introspecção, que não esteja falseado e deformado pelo pensamento da ação a se fazer, mas que seja uma visão direta do espírito por ele mesmo.

\subsection{Bergson, James e a psicologia}

Uma tal visão do espírito por ele mesmo é igualmente o que Bergson crê encontrar na psicologia de James, cujo tratado seria assim constituído por duas metades tal como o será Matéria e Memória: uma psicologia científica de orientação pragmatista e uma psicologia filosófica de orientação espiritualista:

\footnotetext{
Certamente, seus Princípios de Psicologia são de um grande sábio: fundador do primeiro laboratório de psicologia experimental que houve na América, especialmente preparado pelos seus estudos médicos para utilizar os recursos da psicologia patológica, ele soube se beneficiar dos mais novos métodos. E, entretanto, a verdadeira novidade do livro, a sua profunda originalidade, reside na aplicação que o autor fez do procedimento mais antigo, mais conhecido, mais banal: a observação interior. Esse método parecia ter fornecido tudo aquilo que ele poderia dar; e eis que, nas mãos de James, teve o efeito de um instrumento que se colocou à serviço pela primeira vez. Isso que nós havíamos tomado até então como uma descrição dos fatos, aparecia como um tecido de ideias preconcebidas, de hipóteses, de teorias; o véu que se interpõe em cada um de nós, entre nossa consciência e nossa pessoa, caia; apercebia-se a alma humana nua. (BERGSON, 2011, p. 39-40) ${ }^{13}$
}

Ao relê-la, a homenagem parece bem paradoxal. Bergson saúda em James antes o psicólogo da corrente da consciência do que aquele da ação. Ora, ele nada devia ao primeiro: ele próprio havia se explicado sobre essa questão, mostrando como o Ensaio não poderia ter sido derivado do artigo sobre a corrente da consciência que James publicou em 1884 (BERGSON, 2011, p. 19) ${ }^{14}$. Nessa época, Bergson apenas conhecia de James seu artigo sobre o esforço e sobre as emoções, que ele cita em DI. Em troca, nenhuma palavra é dita sobre a influência que os Principles, que desta vez ele já havia lido, pôde ter sobre Matéria e Memória. Não deve Bergson mais ao fundador do primeiro laboratório de psicologia experimental dos Estados Unidos do que ao mestre americano da introspecção?

Com efeito, a imagem do psicólogo científico mudou totalmente de um livro ao outro. No Ensaio, a psicologia será ou não será metafísica. Uma psicologia científica está condenada a ilusões, como o mostram a psicofísica alemã ou a psicologia associacionista inglesa. Em Matéria e Memória, a psicologia 
científica, tanto sob a forma da psicofisiologia como da psicopatologia, nos dá, ao contrário, verdadeiros conhecimentos sobre o espírito, se ela toma como fio condutor o caráter utilitário das funções mentais. No Ensaio, é uma tal psicologia, grosseira e enganada pela linguagem, que provoca falsos problemas na filosofia quando infelizmente os filósofos aceitam os seus termos (os quais a própria psicologia emprestou do sentido comum e da vida prática). Em Matéria e Memória, é a psicologia que é preciso proteger da má filosofia cujo ponto de vista intelectualista desnatura seus objetos, como se se pensasse por pensar antes do que para agir. Acreditamos poder localizar essa virada exatamente na mudança de sentido que sofre a noção de "vida prática": fonte de ilusões para o estudo do espírito quando significava vida social, ela devém fonte de verdades - mesmo parciais - quando viver passa a significar agir.

\section{NOTAS}

1. Tradução realizada por Tiago Rickli, doutorando em Filosofia do PPGFIL/UFPR.E-mail: tiago.rickli@gmail.com

2. Este artigo foi publicado originalmente em francês sob o título "Vie pratique et pragmatisme chez Bergson", In: Shin, A.; Fugita, H.; Sugimura, Y. (org.) Considérations inactuelles. Bergson et la philosophie française au XIXe siècle. Hildeshem-Zürich-NewYork: OLMS, 2017.

3. [Nota do tradutor] Madelrieux faz referência aqui a um dos trabalhos de Arman (Arman Fernandez), no qual 59 carros se encontram empilhados e imobilizados em 1600 toneladas de concreto. A obra de 20 metros de altura é chamada pelo artista de Long term parking.

4. As obras de Bergson estão citadas segundo a paginação e as abreviações utilizadas na edição crítica da PUF (dir. F. Worms). DI, para Essai sur les données immédiates de la conscience (Ensaio sobre os dados imediatos da consciência); MM para Matière et Mémoire: Essai sur la relation du corps à l'esprit (Matéria e Memória: Ensaio sobre a relação do corpo com o espírito); EC para Évolution Créatrice (Evolução Criadora) e PM para La pensée et le mouvant (O pensamento e o o movente).

5. A esse respeito, um texto nos parece incoerente. Bergson escreve: "Se cada um de nós vivesse uma vida puramente individual, se não houvesse sociedade ou linguagem, apreenderia a nossa consciência a série de estados internos sob essa forma indistinta? Certamente não, pois conservaríamos a ideia de um espaço homogêneo onde os objetos se distinguem claramente uns dos outros, e porque é bastante cômodo alinhar num tal meio (...) os estados de certo modo nebulosos que afetam, num primeiro momento, o olhar da consciência” (BERGSON, 2007, p. 102). Compreende-se que Bergson queira assim lembrar o primado lógico do espaço sobre a linguagem e a sociedade, mas se ele retira a finalidade prática, não se compreende mais em que ainda é "cômodo" espacializar nossos estados de consciência. Se não há vida social, não há nenhum interesse em se espacializar o que não é espacializável, ou então é preciso assumir que se espacializaria "por nada, por prazer", e porque se é "obsessivo" pela ideia de espaço - o que não constitui uma explicação. As demais passagens de Bergson sobre a razão da espacialização da vida interior estão livres de equivocidade: "a razão disso é que nossa vida exterior e, por assim dizer, social, tem mais importância prática para nós do que nossa existência interior e individual" (BERGSON, 2007, p. 97); "uma vida interior em momentos bem distintos, em estados claramente caracterizados, responderá melhor às exigências da vida social” (BERGSON, 2007, p. 103).

6. Esse princípio é fortemente marcado por Bergson quando ele retorna em MM à tese de DI, (BERGSON, 2008a, p. 206, n.s.).

7. Remeto ao índice estabelecido por Camille Riquier em sua edição crítica para verificação (verbete “vida prática”).

8. Não poderíamos deixar de citar um outro trecho desta Introdução como uma magnífica ilustração do movimento retrógrado do verdadeiro no próprio texto que denuncia essa ilusão. Ao voltar à gênese de DI, Bergson escreve: "finalmente, nós acreditamos ter reencontrado a duração interior inteiramente pura (...). Que a ciência positiva não tivesse se interessado por esta duração, nada de mais natural, pensávamos nós: talvez, a sua função seja precisamente a de 
compor para nós um mundo onde possamos, para a comodidade da ação, escamotear os efeitos do tempo" (BERGSON, 2009 b, p. 4, n.s.); e ele continua, sempre no quadro de uma lembrança das conclusões de $D I$, a respeito da inteligência que está "sobretudo destinada a preparar e a esclarecer nossa ação sobre as coisas" (BERGSON, 2009b, p. 6).

9. Empresto o termo de Roberto Frega em sua análise da proposição e do juízo em Dewey, Pensée, expérience, pratique. Étude sur la théorie du jugement de John Dewey, Paris, L’Harmattan, 2006.

10. Permito-me remeter ao meu livro, William James. L'attitude empiriste. Paris: PUF, 2008, cap. III.

11. Camille Riquier, em sua edição de $M M$, nota que M. Manouvrier já havia utilizado em 1884 esta imagem da estação central (cf. BERGSON, 2008a,, p. 319), mas a citação de onde a imagem é extraída não parece tratar do papel de permutação do cérebro, isto é, de sua função intermediária e mediadora tal como nos casos de James e Bergson, mas, antes, trata de seu papel centralizador e federativo.

12. Cf. igualmente BERGSON, 2008c, p. 54, p. 169 e p. 1142 (sobre a explicação na psicologia). A oposição ulterior de Bergson ao darwinismo não é aqui um obstáculo, pois Bergson não se opõe à ideia de vantagens adaptativas, mas apenas ao mecanismo de sua aparição.

13. O aspecto "espiritualista" dessa psicologia é invocado na p. 48.

14. Ver também, carta a Ribbot, 10 de julho de 1905, in Mélanges. Paris: PUF, 1972, pg. 656 a 658.

\section{REFERÊNCIAS}

ANGELL, J. R. 1907. The Province of Functional Psychology. In: The Psychological Review, vol. XIV, n², mars.

BERGSON, H. 2002. Cours surl'« Histoire de l'idée de temps ». In Annales bergsoniennes I. Paris: PUF. p. 52. .2007. Essai sur les données immédiates de la conscience. Éd. critique sur la direction de Fréderic Worms. Paris: PUF.

2008a. Matière et Mémoire: Essai sur la relation du corps à l'esprit. Éd. critique sur la direction de Fréderic Worms. Paris: PUF.

.2008b. L'évolution créatrice. Éd. critique sur la direction de Fréderic Worms. Paris: PUF.

.2008c. Les deux sources de la morale et de la religion. Éd. critique sur la direction de Fréderic Worms. Paris: PUF.

. 2009a. L'énergie spirituelle. Éd. critique sur la direction de Fréderic Worms. Paris: PUF.

.2009b. La pensée et le mouvant. Éd. critique sur la direction de Fréderic Worms. Paris: PUF.

.2011. Sobre o pragmatismo de William James (ed. S. Madelrieux). Paris: PUF.

JAMES, W. 1979. The Will to Believe, in The Works of William James, F. H. Burkhardt, F. Bowers e I. K. Skrupskelis (ed.). Cambridge: Harvard University Press, vol. 6.

. 1981. The Principles of Psychology, in The Works of William James, F. H. Burkhardt, F. Bowers e I.

K. Skrupskelis (ed.). Cambridge: Harvard University Press, vol. 8, t. I. 